\title{
Research
}

\section{Otolaryngology Symptoms and Signs in COVID-19 Patients: A Descriptive Study in Oman}

Salma Mohammed Al Sheibani ${ }^{1 *}$, Shaden Al Riyami ${ }^{1}$, Rabaa Al Kalbani ${ }^{1}$, Ahmed Al Sibani ${ }^{1}$, Sultan Mohammed Al Lawatia ${ }^{2}$, Subirendra Kumar ${ }^{1}$, and Suad Mohammed Al Harthi ${ }^{2}$

${ }^{1}$ Department of Otolaryngology, Al Nahdha Hospital, Muscat, Oman

${ }^{2}$ Department of Medicine, Al Nahdha Hospital, Muscat, Oman

${ }^{\star}$ Correspondence to: Salma Mohammed Al Sheibani, MD; Senior Consultant, Department of Otolaryngology, Al Nahdha Hospital, Muscat, Oman; E-mail: salsheibani@gmail.com

Received: Oct 10 ${ }^{\text {th }}, 2020$; Revised: Oct 14 ${ }^{\text {th }}, 2020$; Accepted: Oct 15 $5^{\text {th }}, 2020$; Published: Oct $16^{\text {th }}, 2020$

Citation: Al Sheibani SM*, Al Riyami S, Al Kalbani R, Al Sibani A, Al Lawatia SM, Kumar S, and Al Harthi SM. Otolaryngology symptoms and signs in COVID-19 patients: A descriptive study in Oman. ENT Open A Open J. 2020; I(1): 9-14.

\begin{abstract}
\section{Objectives}

To conduct a demographic analysis of COVID-19 cases highlighting on the otolaryngology presenting symptoms and signs that developed throughout the course of the disease. The symptoms related to otolaryngology may present early in the natural course of the disease. The literature on otolaryngology manifestations in these patients is scanty even though they can play an important role in suspecting and investigating positive cases early in the course of disease. This can improve not only the outcome of treatment of these cases but also minimize the spread from these cases if remain unsuspected. The final goal is to add these symptoms to the check list which must be completed by the first contact physician.
\end{abstract}

\section{Methods}

The physicians who were directly involved in dealing with confirmed cases of COVID-19 were the participants. An online form was generated and circulated to these physicians. The information gathered was about all presenting symptoms including those related to otolaryngology. Patients belonging to both 'on treatment' and 'quarantine' groups were studied. The patients' data was analyzed after dividing them into various groups.

\section{Results}

A total of 322 patients aged 5 months to 81 years were studied. Fever (71.7\%) and cough (70.18\%) were the top two commonest symptoms. Sore throat was noted in $15.8 \%$. Headache and rhinorrhea were found in $10.24 \%$ and $6.83 \%$ cases respectively. There were $4.04 \%$ cases who presented with loss of taste and smell. Out of the total 322 patients $70.8 \%$ required admission while the others were recommended home quarantine. Ten percent patients required intubation as they were not able to maintain saturation by all other means.

\section{Conclusions}

The otolaryngology manifestation in our study is under reported in the absence of a check list and lack of awareness in the beginning of the pandemic. The literature is scanty on this issue as the knowledge about this new virus and its behavior is still building. Creating a check list including otolaryngology manifestations and made available in all institutions receiving these patients is essential.

Keywords: COVID-19; ENT manifestation; Otolaryngology manifestation; Loss of taste; Loss of smell; Anosmia. 


\section{INTRODUCTION}

In December 2019, China started to report an outbreak of what was then named COVID-19, caused by the Corona Virus SARS-CoV-2. ${ }^{1}$ This outbreak spread initially in Wuhan city of Hubei Province and within weeks it was declared by the World Health Organization (WHO) as a global epidemic spreading in many cities of China and the rest of the world. ${ }^{2-4}$

The transmission of SARS-CoV-2 occurs through droplet transmission, fecal-oral route, conjunctiva and fomites. ${ }^{5-11}$ COVID-19 has an incubation period and exposed people with no symptoms can carry SARS-CoV-2. ${ }^{12}$ The incubation period ranges from 2 to 14 days with a reported mean incubation period of 6.4 days. ${ }^{13}$ Transmission by an asymptomatic carrier is possible during the incubation period. ${ }^{3,14,15}$

COVID-19 patients were reported to have various clinical presentations. The symptoms were discussed in depth in the WHO-China joint report. ${ }^{4}$ Pyrexia remained the most common presentation noted in $85 \%$ of the cases. Cough is the second most common symptom which was seen in $67.7 \%$ of reported cases. ${ }^{2,5}$ Sputum production was reported in $33.4 \%$ of the patients. ${ }^{2,5}$ Constitutional symptoms such as muscle or bone aches, chills, and headache are seen in $14.8 \%, 11.4 \%$ and $13.6 \%$ of the cases respectively. ${ }^{2,5}$ Respiratory symptoms such as dyspnea, sore throat, and nasal congestion were present in $18.6 \%, 13.9 \%$ and $4.8 \%$ of cases respectively. Few patients reported gastrointestinal symptoms which were seen in less than $5 \%$ of the patients. ${ }^{2,5}$

According to the latest WHO report, number 96, the WHO risk assessment is very high globally. ${ }^{16}$ The situation in the Eastern Mediterranean region is analogous to that of the rest of the world. In the Sultanate of Oman, the number of COVID-19 cases is still growing. Measures have been taken by the government to limit the spread of the virus, including health education and social distancing.

It is crucial to detect the pattern of COVID-19 presentation in the Sultanate of Oman and the symptomatology among our population. In this paper we are aiming to conduct a demographic analysis of COVID-19 cases presented to our accident and emergency and/or admitted to Al Nahda Hospital with a highlight of the otolaryngology related symptoms and signs that developed throughout the course of the disease.

\section{METHODOLOGY}

This study was conducted at Al Nahdha Hospital, Muscat, Ministry of Health, Sultanate of Oman. It was design to extract data from medical records of COVID-19 cases presented to Al Nahdha Hospital accident and emergency department and/or admitted to Al Nahdha Hospital. It specifically evaluated the otolaryngology-related signs and symptoms that developed in these patients.

Ethical approval was granted from the research committee of Al Nahda Hospital and central research committee at Ministry of Health. No consent was required from the patients as it was a retrospective review.

A google online form was designed and distributed to the clinicians who participated in our study. The data were collected from patients' records (Al-Shifa System version 3 plus). Patients included were confirmed to be COVID-19 positive by nasopharyngeal and throat swabs using SARS-CoV-2 RNA PCR.
Participating clinicians filled in the online form, and a spreadsheet with the data was generated. Data collected included patient's age, sex, date of examination presenting symptoms, symptoms severity and history of chronic disease, the need for admission and intubation and the course of the disease.

Most of the studied patients presented with more than one symptom, and accordingly each symptom was looked at separately. The total number of patients presented with each symptom was recorded.

The course of the disease was studied, and categorized into "under quarantine" or "under inpatient care". Patients who were under admission during the data collection process and receiving treatment, were counted under the category of "On treatment" and patients who were discharged on medications to either their homes or to an institutional quarantine center were counted under the "Quarantine" group.

\section{RESULTS}

A total of 322 patients were evaluated during the period from 23rd of March 2020 until $12^{\text {th }}$ of May 2020. The age ranged from 5 months to 81 years with a mean of 44.1 years \pm 13.8 years. The patients were categorized according to the age into three groups, group A (0-18 years), group B (19-59 years) and group C (60 and above) as shown in Table 1.

Eighty-one patients (25.16\%) were females and 241(74.84\%) were males. [Table 1]

Table 1. Age and sex distribution $(n=322)$

\begin{tabular}{|c|c|c|c|}
\hline Age group n (\%) & $\begin{array}{c}\text { Total number of } \\
\text { patients (n=322) }\end{array}$ & $\begin{array}{c}\text { Total number } \\
\text { of Males n=241 } \\
\mathbf{( 7 4 . 8 4 \% )}\end{array}$ & $\begin{array}{c}\text { Total number of } \\
\text { Females n=81 } \\
\mathbf{( 2 5 . 1 6 \% )}\end{array}$ \\
\hline A: $0-18$ & $8(2.48 \%)$ & $4(1.24 \%)$ & $4(1.24 \%)$ \\
\hline B: $19-59$ & $267(82.92 \%)$ & $207(64.29 \%)$ & $60(18.63 \%)$ \\
\hline C: $\geq 60$ & $47(14.60 \%)$ & $30(9.32 \%)$ & $17(5.28 \%)$ \\
\hline
\end{tabular}

Most of the patients presented with more than one complaint. Cough was the most common complaint ( $n=226,70.18 \%)$, followed by fever $(n=231,71.7 \%)$ and breathing difficulty seen in $56.8 \%$ $(\mathrm{n}=183)$ of our patients.

Various gastrointestinal (GI) symptoms were noted in $26.7 \%$ $(n=86)$, and $15.8 \%(n=51)$ complained of sore throat. Headache and runny nose were less commonly presented, as they were seen in $10.24 \%$ $(n=33)$ and 6.83\% $(n=22)$ patients respectively. [Table 2] Only thirteen patients $(4.04 \%)$ suffered from both loss of taste and olfaction alteration.

Four patients (1.24\%) were asymptomatic. [Table 2]

Table 2. Presenting complaints and the age distribution $(n=322)$

\begin{tabular}{|l|c|c|c|c|}
\hline Age Symptoms & $\mathbf{0 - 1 8 n}(\mathbf{6})$ & $\mathbf{1 9 - 5 9 n}(\mathbf{6})$ & ${ }^{\mathbf{3}} \mathbf{3} \mathbf{( n 0 6}$ & Totaln (\%) \\
\hline Fever & $6(1.86 \%)$ & $192(59.63 \%)$ & $33(10.25 \%)$ & $231(71.7 \%)$ \\
\hline Cough & $66(20.50 \%)$ & $188(58.39 \%)$ & $32(9.94 \%)$ & $226(70.18 \%)$ \\
\hline Breathing difficulty & $2(0.62 \%)$ & $163(50.62 \%)$ & $18(5.59 \%)$ & $183(56.8 \%)$ \\
\hline GI symptoms & $5(1.55 \%)$ & $71(22.05 \%)$ & $10(3.11 \%)$ & $86(26.7 \%)$ \\
\hline Sore throat & $1(0.31 \%)$ & $43(13.35 \%)$ & $7(2.17 \%)$ & $51(15.8 \%)$ \\
\hline Headache & $1(0.31 \%)$ & $26(8.07 \%)$ & $6(1.86 \%)$ & $33(10.24 \%)$ \\
\hline Runny nose & $2(0.62 \%)$ & $16(4.97 \%)$ & $4(1.24 \%)$ & $22(6.83 \%)$ \\
\hline Loss of taste & $0(0.00 \%)$ & $11(3.42 \%)$ & $2(0.62 \%)$ & $13(4.04 \%)$ \\
\hline Olfaction alteration & $0(0.00 \%)$ & $11(3.42 \%)$ & $2(0.62 \%)$ & $13(4.04 \%)$ \\
\hline Asymptomatic & $0(0.00 \%)$ & $4(1.24 \%)$ & $0(0.00 \%)$ & $4(1.24 \%)$ \\
\hline Others & $3(0.93 \%)$ & $56(17.39 \%)$ & $11(3.42 \%)$ & $70(21.7 \%)$ \\
\hline
\end{tabular}


We further studied those patients with otolaryngology manifestations. Sore throat, runny nose, loss of taste, olfactory alteration and hoarseness of voice were the reported otolaryngology manifestations. Patients with at least one of the above-mentioned symptoms were considered as patients with otolaryngology manifestations. Eighty-two patients $(25.47 \%, \mathrm{CI}=21.02-30.49)$ had at least one of the above-men- tioned symptoms. Out of them, $81.71 \%(\mathrm{CI}=71.99-88.60)$ were in the age group 19 to 59 years. The majority were males ( $n=67,78.05 \%)$, and 40 of them $(48.78 \%)$ had a chronic illness. Sixty-two out of the 82 patients $(75.6 \%, \mathrm{CI}=65.31-83.62)$ with otolaryngology manifestations required admission, however, 70 of them $(85.37 \%, \mathrm{CI}=76.14-91.43) \mathrm{did}$ not require any assisted ventilation. [Table $3 \& 4$ ]

Table 3. Characteristics of patients who presented with at least one of the otolaryngologic manifestations $(n=82)$

\begin{tabular}{|c|c|c|c|c|c|c|c|c|c|c|c|}
\hline \multirow{2}{*}{$\begin{array}{l}\text { Patients with } \\
\text { otolaryngology } \\
\text { symptomsn(\%) }\end{array}$} & \multicolumn{3}{|c|}{ Age group } & \multicolumn{2}{|c|}{ Sex distribution } & \multicolumn{2}{|c|}{ Chronic illness } & \multicolumn{2}{|c|}{ Intubation } & \multicolumn{2}{|c|}{ Admission } \\
\hline & $0-18$ & $19-59$ & $\geq 60$ & Male & Female & Yes & No & Yes & No & yes & no \\
\hline $\mathrm{n}=82(25.47 \%)$ & 0 & 67 & 15 & 64 & 18 & 40 & 42 & 12 & 70 & 62 & 20 \\
\hline $\mathrm{CI}=95 \%$ & $\begin{array}{l}0 \%(0.00- \\
04.48)\end{array}$ & $\begin{array}{l}81.71 \% \\
(71.99-88.60\end{array}$ & $\begin{array}{l}18.29 \% \\
(11.41-28.01)\end{array}$ & $\begin{array}{l}78.05 \% \\
(67.95-85.64)\end{array}$ & $\begin{array}{l}21.95 \% \\
(14.36-32.05)\end{array}$ & $\begin{array}{l}48.78 \% \\
(38.26-59.41)\end{array}$ & $\begin{array}{l}51.22 \% \\
(40.59-61.74)\end{array}$ & $\begin{array}{l}14.63 \% \\
(8.57-23.86)\end{array}$ & $\begin{array}{l}85.37 \% \\
(76.14-91.43)\end{array}$ & $\begin{array}{l}75.6 \% \\
(65.31-83.62)\end{array}$ & $\begin{array}{l}24.39 \% \\
(16.38- \\
34.69)\end{array}$ \\
\hline Subtotal & \multicolumn{3}{|c|}{82} & \multicolumn{2}{|c|}{82} & \multicolumn{2}{|c|}{82} & \multicolumn{2}{|c|}{82} & \multicolumn{2}{|c|}{82} \\
\hline
\end{tabular}

Table 4. Age, sex distribution and chronic illness in patients who presented with at least one of otolaryngology symptoms

\begin{tabular}{|c|c|c|c|c|c|c|c|c|}
\hline \multirow[t]{2}{*}{ Symptoms } & \multirow[t]{2}{*}{ n (\%) } & \multicolumn{3}{|c|}{ Age group n(\%) } & \multicolumn{2}{|c|}{ Sex distribution n(\%) } & \multicolumn{2}{|c|}{ Chronic illness n(\%) } \\
\hline & & $0-18$ & 19-59 & $\geq 60$ & Male & Female & Yes & No \\
\hline Sore throat & $51(62.20 \%)$ & $1(1.22 \%)$ & $43(52.44 \%)$ & $7(8.54 \%)$ & $39(47.56 \%)$ & $12(14.63 \%)$ & $42(51.22 \%)$ & $9(10.98 \%)$ \\
\hline Runny nose & $22(26.83 \%)$ & $2(2.44 \%)$ & $16(19.52 \%)$ & $4(4.88 \%)$ & $12(14.63 \%)$ & $10(12.19 \%)$ & $11(13.41 \%)$ & $11(13.41 \%)$ \\
\hline Loss of taste \& olfactory alteration & $13(15.85 \%)$ & $0(0.00 \%)$ & $11(13.41 \%)$ & $2(2.44 \%)$ & $11(13.41 \%)$ & $2(2.44 \%)$ & $6(7.32 \%)$ & $7(8.54 \%)$ \\
\hline Hoarseness of voice & $1(1.22 \%)$ & $0(0.00 \%)$ & $0(0.00 \%)$ & $1(1.22 \%)$ & $0(0.00 \%)$ & $1(1.22 \%)$ & $1(1.22 \%)$ & $0(0.00 \%)$ \\
\hline
\end{tabular}

Total of 13 patients (15.85\%) were reported altered olfaction and taste sensation. None were less than 18 years, eleven of them $(84.62 \%)$ were in the middle age group, and only $2(15.38 \%)$ of them were $\geq 60$ years. Most of these patients were males $11(84.62 \%, C I=57.77$ 95.67). Six out of thirteen had an ongoing chronic illness $(46.15 \%$, CI $=23.21-70.86)$. On a further follow up, all of these patients reported recovery of their smell and taste. One 64-year-old female patient presented with hoarsens of voice and mild pneumonia. She was a known case of asthma, diabetes and hypertension. She did not require admission and was discharged for home quarantine. Other secondary symptoms such as chest pain /tightness $(n=30,9.32 \%)$ body ache $(n=27,8.38 \%)$, lethargy $(\mathrm{n}=8,2.48 \%)$, rash $(\mathrm{n}=5,1.55 \%)$, palpitation $(\mathrm{n}=2,0.62 \%)$, gloves and stocking ( $\mathrm{n}=1,0.31 \%)$ were reported variably. Out of the 322 patients, $70.8 \%(\mathrm{n}=228)$ patients were admitted in our hospital, which is a secondary level health care centre, while $29 \%(n=94)$ were discharged to either home or institutional quarantine. This can be attributed to the fact that these patients were referred from primary care centres to our hospital for secondary care.

Intubation was required in $14.5 \%(n=33)$ of admitted cases at some point of time during the course of treatment, and $85.53 \%(n=195)$ of the admitted cases did not require any assisted ventilation. None of the intubated patients were under 18 years, 26 of the intubated patients (78.8\%) were in age group B (19-59 years), and 7 (21.2\%) were in group C $(\geq 60)$.

Out of the total number of intubated patients 33 (10.24\%), 16 out of 33(4.97\%) patients had chronic illness. [Table 5] The patients who were intubated were above 18 years, and the majorities of intubated patients were in the age group B (19-59) and have chronic illness. The total number of patient who have chronic illness were $140(n=140 / 322)$ constituting $43.48 \% \%$ of our study. Most of the patients had multiple chronic illnesses. The most commonly encountered chronic illness is diabetes $(n=88 / 242,27.32 \%)$, followed by hypertension $(n=69 / 242$, $21.42 \%)$ and then dyslipidemia $(n=42 / 242,13.04 \%)$. [Table 5]

Table 5. Presence of chronic illness in 322 COVID-19 patients, with intubation rate

\begin{tabular}{|l|c|c|c|}
\hline $\begin{array}{l}\text { History of a chronic } \\
\text { illness }\end{array}$ & Not Intubated & intubated & Subtotal \\
\hline $\begin{array}{l}\text { Patients with a chronic } \\
\text { illness }\end{array}$ & $\mathbf{1 2 4} \mathbf{( 3 8 . 5 1 \% )}$ & $\mathbf{1 6}(\mathbf{4 . 9 7 \% )}$ & $\mathbf{1 4 0}(\mathbf{4 3 . 4 8 \%})$ \\
\hline Diabetes & $76(23.60 \%)$ & $12(3.73 \%)$ & $88(27.33 \%)$ \\
\hline Hypertension & $58(18.01 \%)$ & $11(3.42 \%)$ & $69(21.42 \%)$ \\
\hline Dyslipidemia & $28(8.70 \%)$ & $4(1.24 \%)$ & $32(9.94 \%)$ \\
\hline Cardiovascular diseases & $13(4.03 \%)$ & $4(1.24 \%)$ & $17(5.28 \%)$ \\
\hline COPD & $1(0.31 \%)$ & $0(0.00 \%)$ & $1(0.31 \%)$ \\
\hline Asthma & $17(5.28 \%)$ & $1(0.31 \%)$ & $18(5.59 \%)$ \\
\hline CKD & $3(0.93 \%)$ & $0(0.00 \%)$ & $3(0.93 \%)$ \\
\hline Immunocompromised & $4(1.24 \%)$ & $0(0.00 \%)$ & $4(1.24 \%)$ \\
\hline $\begin{array}{l}\text { Patients without a } \\
\text { chronic illness }\end{array}$ & $\mathbf{1 6 5}(\mathbf{5 1 . 2 4} \%)$ & $\mathbf{1 7}(\mathbf{5 . 2 8} \%)$ & $\mathbf{1 8 2}(\mathbf{5 6 . 5 2 \% )}$ \\
\hline
\end{tabular}

*The subtotal represents the total number of patients with/without chronic illness, and that is not reflected by the sum of the breakdown of the chronic illnesses, since most of the patients had multiple chronic illnesses.

We further studied the course of the disease. Out of our 322 patients, $234(73 \%)$ were discharged to either home or institutional quarantine, that includes the 94 patients who were discharged from the beginning and did not require admission. Thirty-nine patients $(12.11 \%)$ were still receiving treatment when the data was collected for this paper. Forty-four patients (13.66\%), required an intensive care support and accordingly were transferred to another tertiary hospital with an ICU support to receive optimum required treatment. [Table 6] 
Table 6. Course of the disease and age distribution in 322 COVID-19 patients

\begin{tabular}{|c|c|c|c|}
\hline Age & Quarantine & On treatment & Referred to ICU \\
\hline $0-18$ & $8(2.48 \%)$ & $0(0.00 \%)$ & $0(0.00 \%)$ \\
\hline $19-59$ & $202(62.73 \%)$ & $31(9.63 \%)$ & $35(10.87 \%)$ \\
\hline$\geq 60$ & $29(9.00 \%)$ & $9(2.79 \%)$ & $9(2.79 \%)$ \\
\hline Subtotal & $239(74.22 \%)$ & $39(12.11 \%)$ & $44(13.66 \%)$ \\
\hline
\end{tabular}

\section{DISCUSSION}

COVID-19 infection presents with a set of variable clinical manifestations ranging from no symptoms to a multi-organs failure. ${ }^{17-19}$ However the exact clinical picture is still vague and the discovery of new symptoms is still going on. There is a high viral load in the nasopharyngeal and oropharyngeal secretion, and these sites are the main site of taking the swab sample for testing. ${ }^{20}$ The literature on otolaryngology manifestations is still scanty and there is a need to identify these symptoms precisely.

Our study showed male predominance and in middle age group. Zheng $\mathrm{F}$ et al. reported a male predominance among infected patients with COVID $19 .{ }^{2}$ On the other hand, some studies showed no difference or almost equivalent number of men and women among infected patients. In a study by Zhang et al. the incidence of COVID-19 infection was slightly higher among females. ${ }^{21}$

Kakodkar et al. cited in his literature review, a median age of 47 years in a large study with total of 1,099 COVID-19 patients. ${ }^{5}$ In our study, the calculated median age is equal to 44 years which close to what was reported by Kakodkar et al.

In this study the most common presenting symptoms were cough $(70.18 \%)$, fever (71.7\%) followed by breathing difficulty $(56.8 \%)$. In a study by Chen et al. on 99 patients, the most commonly reported symptoms were fever $(83 \%)$ and cough $(82 \%)$. Shortness of breath was reported as the third most common presenting symptom, and was seen in $31 \%$ of patients. ${ }^{22}$

Guan et al. surveyed 1,099 patients and reported cough to be the commonest presenting symptoms, constituting $67 \%$, followed by shortness of breath in $18.7 \% .{ }^{23}$ Although there are minor differences in the results between these studies, still they are considered comparable.

On a larger scale, a report of over 55,000 patients reported by WHO fever was reported in $87.9 \%$ of the patients followed by dry cough in $67.7 \%$. Shortness of breath was reported to be the fourth presenting symptom that constitute $18.6 \%$ only. ${ }^{24}$ From these studies and our study, we can conclude that fever, cough and SOB are the most commonly encountered symptoms of COVID 19 infection. Gastrointestinal symptoms were found in $27 \%$ of our patients which is comparable to the incidence reported by Yifanet al. $(n=140)$ that was seen in up to $21 \%{ }^{6}$ However, Kakodkar et al. and Guan et al. $(\mathrm{n}=1,099)$ reported lower incidence of $8 \%$ and $3.8 \%$ respectively. ${ }^{5,23}$ This might be explained by comparatively a smaller sample size of our study.

In this study, 25.47\% ( $\mathrm{n}=82)$ patients gave history of at least one otolaryngology related symptoms. It was found that the most commonly encountered otolaryngology symptoms were sore throat $(62.20 \%)$ followed by runny nose $(26.83 \%)$, olfaction alteration with loss of taste (15.85\%) and hoarseness of voice was reported by one patient. Compa- rable to the current report, Dzieciatkowski et al. reported sore throat in $13.9 \%$, which is similar to the rate reported by WHO. ${ }^{24,25}$ Chenet al. reported $5 \%$ of patients presented with sore throat and $4 \%$ with runny nose. $^{22}$

El-Anwar et al. in a systematic review of 11 studies, evaluated the otolaryngology manifestations of over 1,700 COVID-19 positive patients and found the symptoms to present in this order: sore throat $(11.3 \%)$, smell affection (6\%), nasal congestion (4.1\%), nasal obstruction (3.4\%) and runny nose (2.1\%). ${ }^{26}$ The Australian group reported that a higher percentage of patients presented with sore throat and runny nose in $46 \%$ and $40 \%$ respectively. ${ }^{27}$

During the data collection we found that olfaction alteration and loss of taste were reported separately as two separate complaints. However, when we followed up these patients and inquired about the symptoms, we found that all of them had a combination of both symptoms at presentation. These symptoms were temporary and resolved after recovery from the infection in all patients.

Lovato et al. reported $18.6 \%$ of patients having a combination of loss of taste and olfaction alterations while $33.9 \%$ of the patients having at least one of them. ${ }^{28}$ Our study has a lower incidence of these symptoms which may be attributed to under reporting of these two symptoms. This could be explained by the focus at the beginning of the COVID 19 pandemic towards the other more severe symptoms and stabilizing the patients. The attention to these late symptoms of altered olfaction and taste came later.

One explanation for the effect on olfaction has been made by Whitcroft and Hummel, as there is a high expression of angiotensin converting enzyme 2 receptor in the nasal mucosa. ${ }^{29}$ These receptors are acting as entry point for SARS-Cov- $2 .^{30}$ The inflammatory changes which happen due to the disruption of cells in the olfactory neuroepithelium lead to impairment of olfactory receptor neuron, which subsequently lead to damage and/ or impair the neurogenesis. The effect of these changes is usually transient but may last for long time. The symptoms of altered taste sensation could be explained by the impairment of the retro-nasal olfaction rather than the impairment of gustatory system, even though the direct effect of SARS-CoV-2 could not be excluded. ${ }^{29}$

WHO reported headache to be present in $13.6 \%$ and Chenet al. reported similar rate of $8 \%{ }^{22,24}$ Moreover, Yifanet al. and Dzieciatkowski et al. reported higher rates of $19.3 \%$ and $53 \%$ respectively. ${ }^{6,25}$ However, in our study headache was seen in only $11.2 \%$.

We have found four asymptomatic patients at time of presentation who came for contact screening. One of them was found to be desaturating even though being asymptomatic and eventually the patient required a ventilatory support and was intubated. Ishikawa et al. reported a similar case of a patient presented with pneumonia without respiratory symptoms. ${ }^{31}$ On the other hand, WHO found that some of the relatively rare cases who were asymptomatic eventually developed symptoms later on during the course of the disease. ${ }^{24}$

In our study $33(10.25 \%)$ of the patients were intubated. Sixteen patients $(4.97 \%)$ were known cases of chronic illnesses. The median age of intubated patients with chronic illness is 53 years, in comparison to median age of 36 years in those who were intubated but did not have any chronic illnesses. 
The most commonly encountered chronic illness was diabetes followed by hypertension and dyslipidemia. Among 663 patients studied by Zhang et al. $14.4 \%$ were classified to be critical and required intubation with median age of 67 years; $66 \%$ of them were having coexisting chronic diseases. There was a significant correlation between the severity of the symptoms and the presence of chronic illness such as respiratory, cardiovascular, endocrine and inflammatory disease in this study. ${ }^{21}$

Guan et al. reported $5 \%$ of their patients were admitted in ICU, $2.3 \%$ of them required mechanical ventilation and $1.4 \%$ died. Oxygen therapy was administered in $41.3 \%$ and mechanical ventilation in $6.1 \%$. The median age of severe course of the disease in this study was reported to be 47 years. Coexisting illness was found to be more common among this group of patients. ${ }^{23}$

Those who required intubation in our study had chronic illnesses, which is similar to what was reported by Zhang et al. and Guan et al..$^{21,23}$

We suggest creating a pre-set form consisting a check list of symptoms to be used for every patient suspected to have COVID-19. The form should include all reported symptoms including otolaryngology manifestations. This will help in achieving uniformity and more accurate reporting of otolaryngology manifestations. All health care staff should be familiarised with these additional and less common early or late manifestations. These symptoms may be the only presenting symptom in some patients. The community awareness programs should also be directed towards education about these symptoms which might be the only presenting symptoms and should not be ignored. Primary contact physicians too must enquire about these symptoms proactively since the unaware patients may not volunteer this information on their own.

\section{CONCLUSIONS}

Otolaryngology manifestations is a significant part in assessing patients with COVID-19. Reporting otolaryngology symptoms cannot be undervalued. Creating a check list form including otolaryngology manifestations is essential to be added in the list of symptoms that should be inquired from COVID-19 suspected patients and should be available in all institutions dealing with these patients.

\section{ACKNOWLEDGEMENT}

The statistical analysis was done by Mr Nasser Hamed AlSaadi, Assistant supervisor of health information management (Medical statistician) at Al Nahdha hospital.

\section{CONFLICTS OF INTEREST}

None.

\section{REFERENCES}

1. Ozma MA, Maroufi P, Khodadadi E, et al. Clinical manifestation, diagnosis, prevention and control of SARS-CoV-2 (COVID-19) during the outbreak period. Infez Med. 2020; 28(2): 153-165.

2. Zheng F, Tang W, Li H, et al. Clinical characteristics of 161 cases of corona virus disease 2019 (COVID-19) in Changsha. Eur Rev Med Pharmacol Sci. 2020; 24(6): 3404-3410. doi: 10.26355/eurrev_202003_20711

3. Lai C-C, Shih T-P, Ko W-C, et al. Severe acute respiratory syndrome coronavirus 2 (SARS-CoV-2) and coronavirus disease-2019 (COVID-19): The epidemic and the challenges. Int J Antimicrob Agents. 2020;

\section{5(3): 105924. doi: 10.1016/j.ijantimicag.2020.105924}

4. Luo H, Tang Q, Shang Y, Liang S, Yang M, Robinson N, et al. Can Chinese Medicine Be Used for Prevention of Corona Virus Disease 2019 (COVID-19)? A Review of Historical Classics, Research Evidence and Current Prevention Programs. Chin J Integr Med. 2020; 26(4): $243-$ 250. doi: $10.1007 / \mathrm{s} 11655-020-3192-6$

5. Kakodkar P, Kaka N, Baig M. A Comprehensive Literature Review on the Clinical Presentation, and Management of the Pandemic Coronavirus Disease 2019 (COVID-19). Cureus [Internet]. 2020 Apr 6 [cited 2020 Jun 25]; Available from: https://www.cureus.com/articles/29670a-comprehensive-literature-review-on-the-clinical-presentation-andmanagement-of-the-pandemic-coronavirus-disease-2019-covid-19

6. Yifan T, Ying L, Chunhong G, et al. Symptom Cluster of ICU Nurses Treating COVID-19 Pneumonia Patients in Wuhan, China. Journal of Pain and Symptom Management. 2020; 60(1): e48-e53. doi: 10.1016/j. jpainsymman.2020.03.039

7. Chan JF-W, Yuan S, Kok K-H, et al. A familial cluster of pneumonia associated with the 2019 novel coronavirus indicating person-toperson transmission: A study of a family cluster. The Lancet. 2020; 395(10223): 514-523. doi: 10.1093/infdis/jiaa077

8. Liu J, Liao X, Qian S, et al. Community Transmission of Severe Acute Respiratory Syndrome Coronavirus 2, Shenzhen, China. Emerging Infectious Diseases journal - CDC. 2020; 26(6).

9. Tang A, Tong Z, Wang H, et al. Detection of Novel Coronavirus by RT-PCR in Stool Specimen from Asymptomatic Child, China. Emerging Infectious Diseases journal - CDC. 2020; 26(6).

10. Li Q, Guan X, Wu P, et al. Early Transmission Dynamics in Wuhan, China, of Novel Coronavirus-Infected Pneumonia. New England Journal of Medicine. 2020; 382(13): 1199-1207. doi: 10.1056/NEJMoa2001316

11. Zhang Y, Chen C, Zhu S, et al. Isolation of 2019-nCoV from a Stool Specimen of a Laboratory-Confirmed Case of the Coronavirus Disease 2019 (COVID-19). CCDCW. 2020; 2(8): 123-124.

12. Hou C, Chen J, Zhou Y, et al. The effectiveness of quarantine of Wuhan city against the Corona Virus Disease 2019 (COVID-19): A well-mixed SEIR model analysis. J Med Virol. 2020; 92(7): 841-848. doi: 10.1002/jmv.25827

13. Kolifarhood G, Aghaali M, Saadati HM, et al. Epidemiological and Clinical Aspects of COVID-19; A Narrative Review. Arch Acad Emerg Med. 2020; 8(1): e41.

14. Bai Y, Yao L, Wei T, et al. Presumed Asymptomatic Carrier Transmission of COVID-19. JAMA. 2020; 323(14): 1406-1407. doi: 10.1001/ jama.2020.2565

15. Qian G, Yang N, Ma AHY, et al. COVID-19 Transmission Within a Family Cluster by Presymptomatic Carriers in China. Clin Infect Dis. 2020; 71(15): 861-862. doi: 10.1093/cid/ciaa316

16. Coronavirus Disease (COVID-19) Situation Reports [Internet]. [cited 2020 Aug 16]. Available from: https://www.who.int/emergencies/ diseases/novel-coronavirus-2019/situation-reports

17. Cascella M, Rajnik M, Cuomo A, Dulebohn SC, Di Napoli R. Features, Evaluation and Treatment Coronavirus (COVID-19). 
18. Zaim S, Chong JH, Sankaranarayanan V, Harky A. COVID-19 and Multiorgan Response. Curr Probl Cardiol. doi: 10.1016/j.cpcardiol.2020.100618

19. Yuki K, Fujiogi M, Koutsogiannaki S. COVID-19 pathophysiology: A review. Clin Immunol. 2020; 215: 108427. doi: 10.1016/j. clim.2020.108427

20. COVID-19 (coronavirus disease) - ENT, Hearing \& Balance.

21. Zhang J, Wang X, Jia X, et al. Risk factors for disease severity, unimprovement, and mortality in COVID-19 patients in Wuhan, China. Clin Microbiol Infect. 2020; 26(6): 767-772. doi: 10.1016/j.cmi.2020.04.012

22. Chen N, Zhou M, Dong X, et al. Epidemiological and clinical characteristics of 99 cases of 2019 novel coronavirus pneumonia in Wuhan, China: A descriptive study. The Lancet. 2020; 395(10223): 507-513. doi: 10.1016/S0140-6736(20)30211-7

23. Guan W, Ni Z, Hu Y, et al. Clinical Characteristics of Coronavirus Disease 2019 in China. $N$ Engl J Med. 2020; 382(18): 1708-1720. doi: 10.1056/NEJMoa2002032

24. Report of the WHO-China Joint Mission on Coronavirus Disease 2019 (COVID-19).

25. Dzieciatkowski T, Szarpak L, Filipiak KJ, et al. COVID-19 challenge for modern medicine. Cardiol J. 2020; 27(2): 175-183. doi: 10.5603/ CJ.a2020.0055

26. El-Anwar MW, Elzayat S, Fouad YA. ENT manifestation in COVID-19 patients. Auris Nasus Larynx. 2020; S0385814620301462. doi: 10.1016/j.anl.2020.06.003

27. COVID-19 National Incident Room Surveillance Team. COVID-19, Australia: Epidemiology Report 7 (Reporting week ending 19:00 AEDT 14 March 2020). Commun Dis Intell (2018). 2020 Mar 19; 44.

28. Lovato A, de Filippis C, Marioni G. Upper airway symptoms in coronavirus disease 2019 (COVID-19). Am J Otolaryng. 2020: 102474. doi: 10.1016/j.amjoto.2020.102474

29. Whitcroft KL, Hummel T. Olfactory Dysfunction in COVID-19: Diagnosis and Management. JAMA. 2020; 323(24): 2512-2514. doi: 10.1001/jama.2020.8391

30. Sungnak W, Huang N, Bécavin C, et al. SARS-CoV-2 entry factors are highly expressed in nasal epithelial cells together with innate immune genes. Nat Med. 2020; 26(5): 681-687. doi: 10.1038/s41591-0200868-6

31. Ishikawa K, Uehara Y, Matsuo T, Mori N. Pneumonia without Respiratory Symptoms. Intern Med. 2020; 59(11): 1469. doi: 10.2169/internalmedicine.4639-20 